\title{
Work Capacity in the Rabbit after Interference with the Suprarenal Giands, the Suprarenal Medulla or the Splanchnic Nerves.
}

\author{
By \\ Kiy osi Syozi. \\ (左子 瀿) \\ (From the Physiological Laboratory of Prof. Y. Satake, \\ Tohoku Imperial University, Sendai.)
}

The rabbit and the rat, deprived of the suprarenal capsules, although they are capable of indefinitely well surviving, are less resistant, though never considerably, against several kinds of poisoning. 1.233) Similar experiments have been now carried out along the same line of thought, that is, in questioning whether double suprarenalectomy, and allied conditions have some influence upon the resistance of animals against prolonged muscular fatigue. This question has been really examined long since by several investigators, and in fact in an endeavour to elucidate the source of the marked myasthenia, characteristic for the Addison's disease.

In 1892 Albanese $e^{4)}$ stimulated frogs and rabbits electrically after extirpating both suprarenal glands; in the latter the experiment was carried out soon after the removal through the lumbar route. The fatigue developed definitely earlier in them than the normal controls. Convulsions were noted in the rabbits deprived of the glands.

This was soon followed by the reports of Boinet ${ }^{5}$ with rats, long surviving the double decapsulation. A revolving cage was used. The time up to the onset of fatigue was mean 68 minutes (25-116 minutes) in 11 decapsulated rats, surviving 155-200 days, and 102

\footnotetext{
1) Oik a wa, Tohoku J. of Exp. Med., 1931, 18, 1.

2) Oikawa, Ibid, 27.

3) Degti, Ibid., 1934, 24, 468. Literature in these papers.

4) Albanese, Arch. Ital. de Biol., 1892, 17, 239.

5) Boinet, C.r. Soc. Biol., 1895, 67, $273 \& 325$.
} 
minutes (66-140 minutes) in 5 normal ones. Two decapsulated rats were dissected in order to be certain of non-occurrence of regeneration of the glands; none was found there. Seven decapsulated rats were capable of resisting for 9 minutes only against electrically stimulating the zinc plate on which the animal was placed, while the normal individuals showed no sign of fatigue at the end of ten minutes stimulation.

The difference was rather very small, apparently contrary to the author's expectation; and the results have been taken by subsequent writers as corresponding pro or against the view that the suprarenals are playing a significant rôle in protecting from the onset of fatigue.

By letting run either on a form of treadmill or in a revolving cage, Stewart and Rogof ${ }^{6)}$ failed to find material difference in conducting muscular exercise between the cats, which were wholly alert after removing one suprarenal gland with either removing of a large portion of the fellow gland or denervating the fellow gland, and the control animals.

Hartman, Waite and Powell fatigued cats by means of a treadmill. They noted: Cats possessing but a single suprarenal, and that denervated, undergo a period of ill health which appears to be more marked than that of control animals. This is indicated by the loss of appetite, loss of weight, change of temperament, weakness and in some instances a subnormal temperature. They noted then: During this period the working power is very much decreased. On the other hand, after regeneration of some of the nerve fibers, health and power to work are regained. Their inference is that epinephrine plays a very important rôle in increasing muscular work and delaying the onset of fatigue.

In the treadmill experiment, Mauerh of $\mathrm{r}^{8)}$ observed an earlier onset of fatigue in the doubly decapsulated rats and a so operated guinea-pig. The former were used from two days to one month or later after the removal, and the latter a week thereafter. While the control rats, normal and unilaterally decapsulated, were capable of working for 160 minutes, the doubly decapsulated only for fifty minutes. One hundred minutes and 40 minutes were the figures for guinea-pigs respectively.

6) Stewart and Rogoff, J. of Pharm. \& Exp. Ther., 1922, 19, 87.

7) Hartman, Waite and Powell, Am. J. of Physiol., 1922, 60, 255.

8) Manerh of er, Ztschr. f. Biol., 1922, 74, 147. 
Marti ${ }^{9}$ reported from the same Laboratory with $M$ a u erhofer, that the double decapsulation never reduces the resistance of rats against anoxaemia, while some reduction sets in when the testis is removed besides the suprarenals. Accessory cortical tissues are found on or near the testis. In the experiments of Mau erh of er, the suprarenals were the only organs removed.

Erni, ${ }^{10}$ further from the same Laboratory, reported that the press juice from the muscle tissue in the rat, doubly decapsulated and fatigued, accelerates fatigue in another rat, doubly decapsulated, when intraperitoneally introduced. Such juice had no effect upon the rat with intact suprarenals, and the juice from the rat with intact suprarenals also no effect upon the rat without suprarenals but fatigued.

In respect to the voluntary activity, Durrant ${ }^{11)}$ found a marked diminution in the rats deprived of the suprarenals, while they looked normally alert and active. Most of them were tried in the activity cages for periods varying from three days to seven weeks.

Sundberg ${ }^{12)}$ caused the rabbits, surviving the double suprarenalectomy from two weeks to eight months, running by means of either induction shock through the zinc plate or brush or the tread. They inclined to become fatigued distinctly readily. The time elapsing to the onset of fatigue was estimated in the tread experiments, for example, as 15 and 25 minutes in two normal individuals, and 2 and 3 minutes in two decapsulated ones. Rats, decapsulated 4-15 hours previously, fatigued much quicker.

Gans and Mile $y^{13}$ carried out ergographic study on rats under amytal, the sciatic nerve being faradically stimulated. In the rats, which were deprived from the suprarenals 1-11 days previously, a complete fatigue developed in 10-60 minutes, while a fatigue set in in normal individuals in a variable period of from 8 to 26 hours.

$\mathrm{Küh}{ }^{1 i)}$ stimulated electrically gastrocnemius muscle directly. While stimulation for 7-9 hours did not bring about fatigue in the normal guinea-pigs, it set in often within 1-2 minutes in cases of the doubly decapsulated. In his hands guinea-pigs were capable of surviving only 6-12 hours, and at most 20 hours. When stimulation was begun to apply shortly after the decapsulation, the fatigue set in slowly.

9) M a rti, Ztschr, of Biol, 1923, 77, 181.

10) Erni, Ibid., 1923, 78, 315.

11) Durrant, Am.J. of Physiol., 1924, 70, 344.

12) Sund berg, Studien über die Blutzuckerregulation bei epinephrektomierten Tieren, Stockholm 1925, $71 \mathrm{ff}$.

13) G ans and Miley, Am. J. of Physiol., 1927, 82, 1.

14) K ü h l, Pfüger's Arch., 1927, 215, 277. 
This experimentalist suggested the possessing of active accessory cortical tissue if the guinea-pig is capable of surviving more than 20 hours..$^{15}$ )

Beneficial effect of the extract from the cortical tissue was noted in this paper.

By the ergographic study on rabbits, Ferreira de Mira and Joaquim F onte ${ }^{16}$ saw a quick development of fatigue 5-6 days after the double suprarenalectomy, carried out through the abdominal way. Adrenaline acts rather harmfully.

According to Stefl, ${ }^{17}$ ) the extract from the bovine suprarenal gland, not containing adrenaline or choline, suppresses muscular fatigue in frogs.

While Cann on with his co-workers ${ }^{18)}$ were able to observe a beneficial effect of small doses of adrenaline, subcutaneously given into dogs exhausted by running, to recover their ability to run, no reduction resulted in the capacity for long-continued labour by removing one suprarenal and denervating the fellow.

According to Ferreira de Mira with a co-worker ${ }^{19)}$ it depends on dosage whether adrenaline acts beneficially or detrimentally upon the muscular fatigue in rabbits, 0.02-0.0002 $\mathrm{mgrm}$. per kilo being beneficial and $0.02-0.2 \mathrm{mgrm}$. detrimental. Not only adrenaline but also extract of the whole suprarenal gland or its cortex acts to recuperate when given to the animal, normal or decapsulated.

$\mathrm{Bacq},{ }^{20)}$ who determined the spontaneous activity of the rats by means of revolving cages, detected no effect of the abdominal sympathectomy and suprarenal inactivation upon the voluntary activity, except during the first ten days after the operation, when the activity was determined slightly below that of their controls. He removed the right suprarenal gland and the left coeliac ganglion and cut the left splanchnic nerves.

In an ergographic study Ferreira de $\mathrm{Mira}$ with his co-adjutor ${ }^{21)}$ observed no difference in respect to muscular fatigue between the normal rabbits and the rabbits surviving well the double suprarenalectomy two months, without any sign of suprarenal deficiency.

15) Compare the literature summarized in Kojima, Tohoku J. of Exp. Med., $1929,13,228 \& 231$. 1011.

16) Ferreira de Mira and Joaquim Fontes, C.r. Soc. Biol., 1928, 98, 987;

17) St ef 1 , Ibid., 1928, 99, 985.

18) Campos, Cannou, $\mathrm{L} u$ ud in and Walker, Am. J. of Physiol., 1929, 87, 680. 221.

19) Ferreira de Mira et Joaquim Fontes, Arch. Port. d. Sc. Biol., 1929, 2,

20) B ac q, Endocrinology, 1931, 15, 34.

21) Ferreira de Mira and Joaquim Fontes, C.r. Soc. Biol., 1931, 107, 1167. 
In ergographic studies on rats, Ingle with his co-workers ${ }^{2: 3)}$ observed a considerably accelerating effect of the loss of suprarenal glands upon development of muscular fatigue.

When the excised glands were transplanted on the ovaries, the cortical tissue well survived, while the medullary underwent degeneration entirely. They noted further that six animals whose transplanted suprarenals were removed, showed overt symptoms of suprarenal insufficiency and died within twenty days. Kendall's preparation of the suprarenal cortex was tried by them with striking results. It not only prevents the breakdown, but also a recovery sets in.

Thus, while some experimentalists as Stew art and Rogoff and Cannon with his co-workers failed to find any significance of the epinephrine secretion upon the development of fatigue by prolonged muscular work, another writer as $\mathrm{H}$ artman lay some stress upon it. Some other experimentalists who were able to observe a quick onset of fatigue in the animals deprived of the suprarenal capsules, suggested some significant rôle of the suprarenal cortex; and some experimentalists, such as Ingle, came to recognize a protecting effect of Kendall's preparation against the muscular fatigue. Generally speaking, the velocity with which fatigue develops on muscular work, either voluntarily or forcibly, was, in the experiments above quoted, distinctly greater in the animals deprived of the suprarenals in comparison with the control individuals. Such remarkable inferiority in the resistance of the suprarenalectomized animals reminds us of the outcome of some earlier experimentalists who applied various harmful agencies to the animals, which did not entirely recover from the operation and were suffering from some weakness. ${ }^{(3)}$ The present investigations were started early in 1931, and the outcome has not coincided with the reports appearing meanwhile and quoted above. It will be now given below.

Epinephrine is liberated on muscular work, but only when animals were rendered considerably fatigued, and the degree of augmentation is never excessive. ${ }^{2-1)}$ Muscular work, such as running, causes an enormous acceleration of the wholly denervated heart in dogs; demedullation of the suprarenals reduces the acceleration only insignificantly. ${ }^{25}$ ) The demedullation and the

22) Ingle, Proc. of Soc. for Exp. Biol. \& Med., 1933(-34), 31, 163; Ha les, Haslerud and Ingle, Am. J. of Physiol., 1935, 112, 65; Ingle, Hales and Haslerud, Ibid., 1935, 113, 200; Ibid., 1936, 114, 653; Ingle and Harris, Ibid., 657.

23) See some literature in 1-3.

24) W a da, Seo and A be, Tohoku J. of Exp. Med., 1935, 27, 65; previous literature there.

25) W a d and Z. Kan ow ok a, Jap. J. of Med. Sci., III. Biophysics, 1934, 3, 223.* The details will be published in this Journal by Dr. Z.K. 
splanchnicotomy as well however reduce clearly the size of the paradoxical pupil reaction due to muscular exercise in cats. ${ }^{26}$ )

It is rather generally agreed that adrenaline has beneficial action on the muscular contraction or muscular work, although an opposite view is held by some authors. ${ }^{27}$ ) The influence of muscular exercise upon the epinephrine store of the suprarenal glands will be treated in another paper of the present writer; literatures concerning this question are already quoted almost completely in a paper of $\mathrm{Wada}$ and others. ${ }^{2+)}$

\section{Methons.}

Chiefly male albino rabbits were experimented on, and individuals of about the same body weight were employed in each set of experiments, a normal, a doubly decapsulated, a doubly demedullated and a doubly splanchnicotomized. Decapsulation and demedullation was carried out through the lumbar route in the manner described by Kojima and $\mathrm{Kaiwa}^{298}$ respectively. The latter author laid bare the glands per laparotomiam, but the present writer through the lumbar way. The splanchnic nerves were cut in two sittings per laparotomiam. Ample time, at least 25 days, and for the most part, two to three months were allowed to elapse before starting the work experiments.

For compelling the rabbit to walk a wooden revolving wheel was used, driven by a motor and provided with a revolution counter. The floor of the wheel box was covered with a cotton mat, so that the animal neither slipped nor wounded its limbs. It is needless to say that the animal runs in reverse direction to that of the wheel.

The revolving wheel has a diameter of $120 \mathrm{cms}$., a width of 19 cms. and a circumference of 3.8 meters. Movement was commonly done with a velocity of 4 revolutions a minute.

26) Itikawa, Tohoku J. of Exp. Med, 1936, 28, 1. Previous literature there.

27) Literature in $\mathrm{W}$ ad a, Se o and $\mathrm{Abe}$ (24). In passing, some literatures which were overlooked there and some insufficiency may be supplemented here. To 11): Lapique and N attan-Larrier, C. r. Soe. Biol., 1922, 86, 474 (adrenaline facilitates the recovery from fatigue of the gastrocnemius muscle of the frog and decreases the chronaxie of the fatigued muscle). Ferreira de Mira, C. r. Soc. Biol., 1926, 95, 1284 \& 1587 (adrenaline, extract of total suprarenal, medulla \& cortex of frog, guinea-pig, sheep; frog). H a u ptfeld, C.r. Soc. Biol., 1924, 90, 1083 (Cortico-suprarenal extract; frog, rat). Nice, Green berg and Greenberg, Am. J. of Physiol., 1928, 85, 397 (rat, spontaneous activity, adrenaline harmful for normal rats \& no use for doubly decapsulated). Ingle and Harris, Ibid., 1936, 114, 657 (rats, revolving drum, adrenaline not raise the level of activity).

28) Ko ji in a, Tohoku J. of Exp. Hed., 1929, 13, $206 \mathrm{ff}$.

29) Ka iwa, Ibid., 1933, 21, 1 f. 
In the interval after the operation and the fatigue experiment, some exercises were carried out with a slow rotation of the wheel. With repetition of exercise the work ability increases.

In the fatigue experiment the wheel was revolved with a given. velocity, the behaviour of the animals being watched. When the animal, largely exhausted so that it became incapable not only to run, but also to stand up by itself, it was taken out from the wheel, the respiration, the heart rate and the anal temperature were estimated, besides the general conditions of the animal. These observations were done from time to time until the animal appeared to be recovered from fatigue.

\section{Results.}

Four kinds of animals were tested for resistance against fatigue; 11 normal animals, as the control, 14 doubly suprarenalectomized, 11 doubly medulli-suprarenalectomized, and 14 doubly splanchnicotomized. And the results are reproduced in tabular form, viz. in Tables. I-IV respectively, which are annexed at the terminal of this essay, and outlined in the following paragraphs.

\section{(1) Non-operated, control animals (Table I).}

The animal runs at first actively and steadily as the wheel revolves, but with an elapse of time it runs irregularly, and later lies prone or on its side along a side wall of the wheel, the hind limbs being stretched. As the inclination of body increases too much the animal: begins to run again. The respiration is then very accelerated, and mucus comes out of the nostrils. On revolving the wheel further, the pupils dilate considerably, the animal stumbles and cannot stand on the fore limbs and finally rolls in the cage; as it revolves, the nose or the breast colliding with the wall of the cage. No power to stand up once more, it is completely exhausted, powerless. At this: time the breathing is slow and deep, following by a dyspnoeic period. The heart beats also very frequently. The anal temperature is always high. In almost all cases the animal recovers within thirty minutes from fatigue. It may be further noted that no convulsions were observed in all the normal animals, that is 11.

The time elapsed from the beginning of running till the complete: fatigue in 11 animals is as follows: 


\begin{tabular}{|c|c|c|c|c|c|c|c|}
\hline \multirow{2}{*}{$\begin{array}{l}\text { No. of } \\
\text { rabbit }\end{array}$} & \multirow{2}{*}{$\begin{array}{l}\text { No. of } \\
\text { experi- } \\
\text { ment }\end{array}$} & \multicolumn{6}{|c|}{ Time of running needed for the complete fatigue } \\
\hline & & \multicolumn{2}{|c|}{ Minimum } & \multicolumn{2}{|c|}{ Maximum } & \multicolumn{2}{|c|}{ Mean } \\
\hline 1 & 10 & \multicolumn{2}{|c|}{42 minutes } & \multicolumn{2}{|c|}{233 minutes } & \multicolumn{2}{|c|}{110 minutes } \\
\hline 2 & 9 & & $"$ & 145 & $"$ & 62 & $"$ \\
\hline 3 & 8 & &, & 82 & $"$ & 62 & $"$ \\
\hline 4 & 7 & & 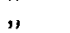 & 43 & $"$ & 29 & $"$ \\
\hline 5 & 5 & & $"$ & 266 & ", & 105 & $"$ \\
\hline 6 & 3 & 71 & ", & 81 & " & 76 & $"$ \\
\hline $7 *$ & 9 & 5 & ", & 31 & ", & 16 & " \\
\hline 8 & 8 & 11 & $"$ & 42 & $"$ & 32 & $"$ \\
\hline 9 & 7 & 26 & " & 63 & $"$ & 48 & ", \\
\hline 10 & 9 & 18 & "I & 80 & $"$ & 39 & " \\
\hline $11^{*}$ & 5 & 7 & ", & 13 & $"$ & 9 & $"$ \\
\hline
\end{tabular}

* Rabbits with this mark are omitted from the general consideration because of their inability to run properly in the revolving wheel.

Rabbit No. 7 was unskillful in running in the revolving wheel in the first five experiments, and Rabbit No. 11 through all the experiments. The mean of the means for 9 individuals, excepting these two which could not be utilized to the proper fatigue test, is $62 \mathrm{~min}-$ utes (249 revolutions, 947 meters).

\section{(2) Doubly suprarenalectomized rabbits (Table II).}

About one month or later after the second decapsulation, which was performed about three or four weeks after the first decapsulation, that is the right side operation, the running experiment was carried out. As above related, some trainings were preceded meanwhile. The last running was tried, from two and half months to one year after the last decapsulation. The doubly decapsulated animals also can run well just as the control animals, and the course or behaviour and symptoms manifested with development of fatigue were similar to the latter. Only they fell down suddenly after some stumbles, and some animals were attacked by convulsion seizures, occasionally followed by death. The time elapsed until development of complete fatigue is as follows:

\begin{tabular}{|c|c|c|c|c|}
\hline \multirow{2}{*}{$\begin{array}{l}\text { No. of } \\
\text { rabbit }\end{array}$} & \multirow{2}{*}{$\begin{array}{l}\text { No. of } \\
\text { experi- } \\
\text { ment }\end{array}$} & \multicolumn{3}{|c|}{ Time of running needed for the complete fatigue } \\
\hline & & Minimum & Maximum & Mean \\
\hline A $1^{*}$ & 4 & 7 minates & 42 minutes & 25 minutes \\
\hline A 2 & 10 & & 5.7 & $\mathbf{3 5}$ \\
\hline A 3 & 13 & 4 & 98 & 29 \\
\hline A 4 & 13 & 10 & 94 & 42 \\
\hline
\end{tabular}




\begin{tabular}{|c|c|c|c|c|c|c|c|}
\hline \multirow{2}{*}{$\begin{array}{l}\text { No. of } \\
\text { rabbit }\end{array}$} & \multirow{2}{*}{$\begin{array}{l}\text { No. of } \\
\text { experi- } \\
\text { ment }\end{array}$} & \multicolumn{6}{|c|}{ Time of running needed for the complete fatigue } \\
\hline & & \multicolumn{2}{|c|}{ Minimum } & \multicolumn{2}{|c|}{ Maximum } & \multicolumn{2}{|c|}{ Mean } \\
\hline A $\mathbf{5}$ & 10 & \multicolumn{2}{|c|}{26 minutes } & \multicolumn{2}{|c|}{107 minntes } & \multicolumn{2}{|c|}{59 minutes } \\
\hline A 6 & 13 & & $"$ & 190 & $"$ & 79 & $"$ \\
\hline A $7 *$ & 4 & & $"$ & 3.5 & $"$ & 3 & $"$ \\
\hline A 8 & 7 & 8 & $"$ & 150 & $"$ & 69 & $"$ \\
\hline A 9 & 4 & 28 & " & 59 & $"$ & 43 & " \\
\hline A 10 & 7 & 3 & " & 29 & $"$ & 16 & $"$ \\
\hline A 11 & 5 & 22 & $"$ & 71 & " & 51 & $"$ \\
\hline A 12 & 4 & 40 & ", & 270 & " & 130 & ", \\
\hline A $13^{*}$ & 5 & 6 & ", & 19 & $"$ & 12 & $"$ \\
\hline $\mathbf{A} 14$ & 8 & 32 & $"$ & 250 & $"$ & 109 & $"$ \\
\hline
\end{tabular}

Among these 14 rabbits, No. A 1 often refused to run, No. A 3 also often very unskillfully and Nos. A $7 \&$ A 13. always unskillfully. The figures from these three rabbits, Nos. A 1, A $7 \&$ A 13, therefore must be taken out of accounting the fatigue time. The mean of the mean fatigue time of 11 individuals is then 62 minutes (247 revolutions, 938 meters). These figures well coincide with the normal, control, above given.

Noteworthy are the following: Rabbit No. A 1 which showed a recovery from fatigue in the fourth test, about one hour later it was attacked by clonic convulsions and three hours later was found dead. Rabbit No. A 5 ran well in the tenth test of fatigue, but a few hours after stopping revolving fatigue continued, and on the next day the animal died. In the fourth experiment Rabbit No. A 9 nearly recovered from fatigue about fifty minutes after discontinuance of running, but a fur ther thirty minutes later it was suddenly attacked by severe tonic convulsions and soon died. Violent convulsions set in Rabbit No. A 6 in the eighth test, 0.5 c.c. of adrenaline chloride Sankyo(1:1000) was injected subcutaneously; twenty minutes later there was no signs of fatigue more; this animal was subsequently placed to the fatigue test several times. As signs of fatigue did not yet disappear two hours after discontinuation of the revolving test, Rabbit No. A 12 was also injected in the second test with 1 c.c. of adrenaline chloride hypodermically. About twenty minutes later the animal became alert. This rabbit died three hours after the fourth fatigue test.

Rabbits A 11, A 13 and A 14 are Rabbits Nos. 1, 3 and 4 in the normal, control series respectively; fatigue set in distinctly earlier in the two former rabbits after doable decapsulation, but the latter showed wholly the reverse. From the outcome in the former two rabbits, it might be deduced that the suprarenals are playing a significant rôle in muscular activity, but not only the 
figures in Rabbit A 14 (viz. Rabbit No. 4 in Table I), reproduced in Tables I \& II, cannot be explained simply by an increasing ability through training, but one should note particularly the general coincidence in the figures in both sets of test.

Although there are thus no material differences rê the time needed for the complete fatigue between both groups of animals, normal and doubly suprarenalectomized, we must recognize a distinct dissimilarity there, that is, severe convulsions occurred in the doubly decapsulated rabbits, while there was no such a case in the normal rabbits. That we had no occasion to see any covulsive attacks in animals with intact suprarenals might be chance, but that the animals, deprived of a large mass of suprarenals, or both glands or the epinephrine secretion, such as to remove one suprarenal gland and to denervate the fellow, were apt to get in convulsions, is commonly known.467;8)

A rabbit of $S u n d b$ erg, ${ }^{12}$ surviving loss of suprarenals by 6 months, which was fatigued by hunting by means of a faradic brush, but found recovered about three and a half hours later, was discovered dead when a further one and a half hours later was brought to observation; this might be an analogous case with ours.

Further, in harmony with most previous reports, ${ }^{24) 27}$ ) adrenaline acts to facilitate recovery from fatigue, whereby its application can guard the animal, worthy of note, against a fatal outcome, sometimes occurring in following convulsive attacks. Some similarity is shown in a work of $\mathrm{Cann}$ on with his co-workers. ${ }^{18)}$

\section{(3) Doubly medulli-suprarenalectomized rabbits (Table III).}

At least about four weeks were allowed to elapse after the demedullation to the first running test, which was repeatedly conducted, and in fact one year or more elapsed in two animals (Rabbits Nos. B 4 \& B 5) after the operation till the last test was terminated. It may be added by way of precaution that a few trainings were carried out before the first test.

The course and symptoms manifested until development of complete fatigue were similar to those given in the descriptions for normal, control rabbits.

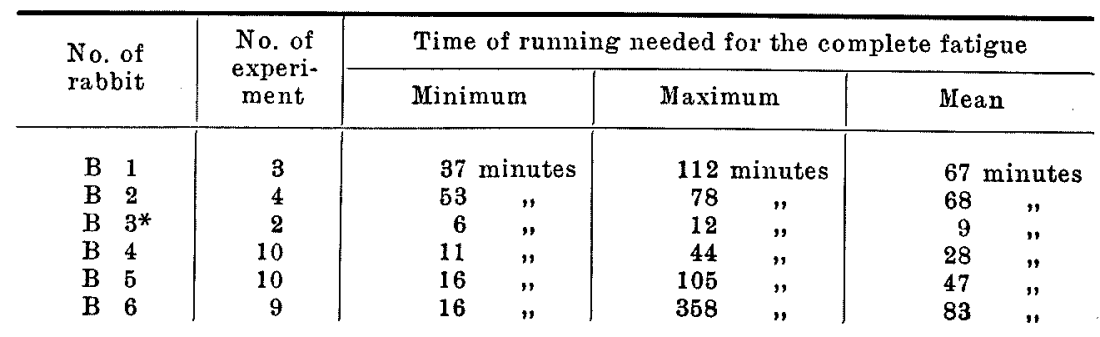




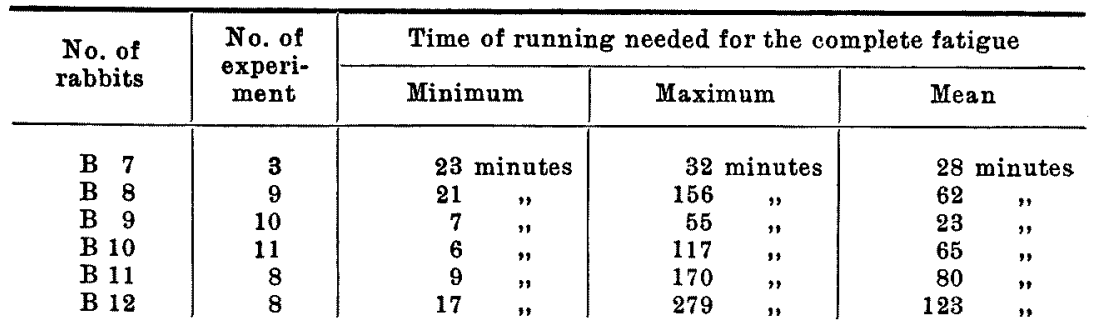

The average of the mean values of 12 individuals is 55 minutes, and that of 11 is 61 minutes (246 revolutions, 935 meters), if Rabbit No. B 3 is excluded from the calculation because of its unskillfulness in running. Such a rabbit cannot be properly used for a fatigue test.

Rabbit No. B 2 was exhausted rather completely in the fourth fatigue test; about fifty minutes after discontinuation of the test the animal scarcely stood up, but soon lay down on its side and two hours later died.

\section{(4) Doubly splanchnicotomized rabbits (Table IV).}

Twenty five days to about two hundred days after double splanchnicotomy the fatigue test was begun in 14 animals, so operated on. There were no peculiarities in the behaviour of these animals other than those in the animals above given. No convulsions were observed.

\begin{tabular}{|c|c|c|c|c|c|c|c|}
\hline \multirow{2}{*}{$\begin{array}{l}\text { No. of } \\
\text { animals }\end{array}$} & \multirow{2}{*}{$\begin{array}{l}\text { No. of } \\
\text { experi- } \\
\text { ment }\end{array}$} & \multicolumn{6}{|c|}{ Time of running needed for the complete fatigue } \\
\hline & & \multicolumn{2}{|c|}{ Minimum } & \multicolumn{2}{|c|}{ Maximum } & \multicolumn{2}{|c|}{ Mean } \\
\hline C 1 & 4 & \multicolumn{2}{|c|}{32 minutes } & \multicolumn{2}{|c|}{151 minutes } & \multicolumn{2}{|c|}{100 minutes } \\
\hline C $2 *$ & 10 & 8 & $"$ & 52 & " & 17 & $"$ \\
\hline C $3^{*}$ & 4 & 4 & " & 14 & " & 7 & ", \\
\hline C $4 *$ & 3 & 6 & $"$ & 12 & " & 8 & $"$ \\
\hline C $5 *$ & 8 & 6 & $"$ & 15 & $"$ & 9 &, \\
\hline C $6^{*}$ & 7 & 6 & $n$ & 12 & ", & 9 & ", \\
\hline C 7 & 7 & 28 & " & 175 & " & 77 & ", \\
\hline C 8 & 5 & $\mathbf{5}$ & ", & 99 & ", & 34 & ", \\
\hline C 9 & 8 & 14 & $"$ & 262 & $"$ & 74 & ", \\
\hline C 10 & 8 & 16 & ", & 50 & ," & 28 & ", \\
\hline C 11 & 5 & 5 & $"$ & 64 & ", & 34 & " \\
\hline C 12 & 10 & 8 & $"$ & 159 & ", & 76 & ", \\
\hline C 13 & 9 & 28 & ", & 123 & " & 74 & $"$ \\
\hline C $14^{*}$ & 8 & 13 & $"$ & 27 & $"$ & 20 & ", \\
\hline
\end{tabular}

The average of the mean values was in this group of animals short, that is 42 minutes, but this is really due to the fact that 6 ani- 
mals (Rabbits Nos. C 2, C 3, C 4, C 5, C 6 \& C 14) were unskillfull in running; if these are excluded from consideration, the average of eight rabbits is 63 minutes (252 revolutions, 958 meters).

In summarizing all the data, excepting the animals showing unskillfulness in running in the revolving wheel, a small table is constructed as follows.

\begin{tabular}{|c|c|c|c|}
\hline & $\begin{array}{l}\text { Time needed } \\
\text { for complete } \\
\text { fatigue }\end{array}$ & $\begin{array}{l}\text { Number of } \\
\text { revolutions } \\
\text { in that spell }\end{array}$ & $\begin{array}{l}\text { Distance of } \\
\text { run }\end{array}$ \\
\hline Cont & 62 minutes & 249 times & 947 met \\
\hline Doubly suprarenalectomized (11 animals) & 62 & $247 "$ & 938 \\
\hline $\begin{array}{l}\text { Doubly medulli-suprarenalectomized } \\
\text { (11 animals) }\end{array}$ & 61 & $246 "$ & 935 \\
\hline Doubly splanchnicotomized ( 8 animals) & 63 & 252 & 958 \\
\hline
\end{tabular}

Work capacity of the rabbit is not influenced materially by depriving the suprarenals, their medulla or the splanchnic nerves. Our animals were surviving indefinitely these operations and behaved alert. In the rabbits, thus long surviving removal of the main suprarenal glands, accessory cortical tissue, which are to be found without exception, enlarges abundantly. ${ }^{3031)}$

The experiments of Stewart and Rog off on cats ${ }^{6}$ whose one suprarenal was removed and another was also largely removed or denervated, those of Cannon with his co-adjustors on dogs ${ }^{18}{ }^{18}$ whose one suprarenal gland was removed and another denervated, and those of Bacq on rats, ${ }^{20}$ whose right suprarenal gland was removed and the left coeliac ganglion and the left splanchnic nerves were interfered with, are to be taken as harmonizing with the present data, and the results of Ferreira de Mira and Joaquim Fontes on rabbits, doubly suprarenalectomized and brought into an ergographic study check well with ours. All the other previous experiments on the animals, deprived of the suprarenals, wholly differ from the present, that is there was a considerably rapid occurrence of fatigue in the animals so operated on. On considering such reports in detail it may however be detected that those animals commonly were not wholly recovered from the injury resulting from the major opera-

30) Ko jima, Tohoku J. of Exp. Med., 1929, 13, 203; 357.

31) Ohguri, Ibid., 1931, 17, 390. 
tions. Any difference rê resistance of animals against hard work, if it exists, should not be accounted for by assuming some rôle of the suprarenal cortex or suprarenal medulla upon the work capacity of the animal but some other conditions deteriolated by the major operation, should be taken into account in delving the causes of reducing the work capacity.

Work capacity of the rabbits, long surviving double suprarenalectomy, medulli-suprarenalectomy or splanchnicotomy is apparently quite the same as the normal individuals. Are they wholly equal in both kinds of animals? Never! The animals, bilaterally suprarenalectomized and then medulli-suprarenalected, are apt to fall into tonic and clonic convulsions and to die sometimes; they, especially the suprarenalectomized ones have thus some smaller resistance against fatigue, definitely though little. This harmonizes well with the findings of $\mathrm{O} i \mathrm{ka} \mathrm{w} \mathrm{a} \mathrm{a}^{12)}$ and $\mathrm{Deg} \mathrm{ti}^{\mathrm{s}}{ }^{3)}$ who tested the susceptibility respectively of rabbits or rats, which were long and well surviving, and found some definite, though small increase of the susceptibility.

Then what is responsible for this small, but definite resistance of the animals, so operated on, against the fatigue? We have a large number of previous discussions on this point. It is quite beyond doubt that epinephrine is liberated on muscular exercise, but it is smaller in magnitude and only sets in when the animal becomes markedly fatigued. ${ }^{2+1}$ And adrenaline acts to guard the animal against detrimental outcome due to fatigue, as our experiments also show. It is thus probable that lack of secretion from the suprarenals, that is a large portion of epinephrine and sympathin secretion can be taken as accounting for the small inferiority of resistance of animals against fatigue. However there are some reasons that one should connect with the insufficiency of the cortical tissue, even though the accessories are abundantly hypertrophied; the behaviour of animals, simply deprived of both suprarenals are not wholly the same as those deprived from the epinephrine secretion in various respects. Application of the suprarenal cortex extract can also contribute towards solving this question. In the above quotation such experiments are related, but whether it was to be taken as a true active principle is questionable excepting Ingle's examples; by this statement it should not be taken that we deny to take the other extract as containing the active principle.

In terminating it may be stated that the rabbits deprived of the suprarenal capsules and surviving well and indefinitely are apparently nothing ab- 
normal appearances, but definitely very tame against our treating. This is the experience in this Laboratory from the time of Kojima, Oikawa and others. This small statement is here added in passing because we are afraid that this has been carelessly omitted when writing our previous publications from this Laboratory.

\section{SUMmary.}

To test the work capacity by means of a revolving wheel were directed normal rabbits, bilaterally suprarenalectomized, medullisuprarenalectomized or splanchnicotomized. The operated animals were indefinitely surviving and looked alert and had the body weight as the control animals.

Some animals in every set were unskillful in running in the revolving wheel, and they are omitted from consideration, as they are not properly qualified for this test.

The figures of the time needed for developing complete fatigue', the number of revolutions or the distance travelled, were practically wholly the same for the four sets of animals. That is, loss of the suprarenal glands, their medulla or the splanchnic nerves, has not material influence upon work capacity of rabbits.

However, there exists a definite difference between the normal animals and the doubly suprarenalectomized. The latter are apt to fall into convulsions, and some individuals died thereupon. The doubly medulli-suprarenalectomized rabbits showed also this tendency, though infrequently. Therefore those animals should be taken as possessing a small, but definite inferiority against detrimental effect of severe exhaustion. Adrenaline hydrochloride showed some beneficial influence upon this detrimental condition. 


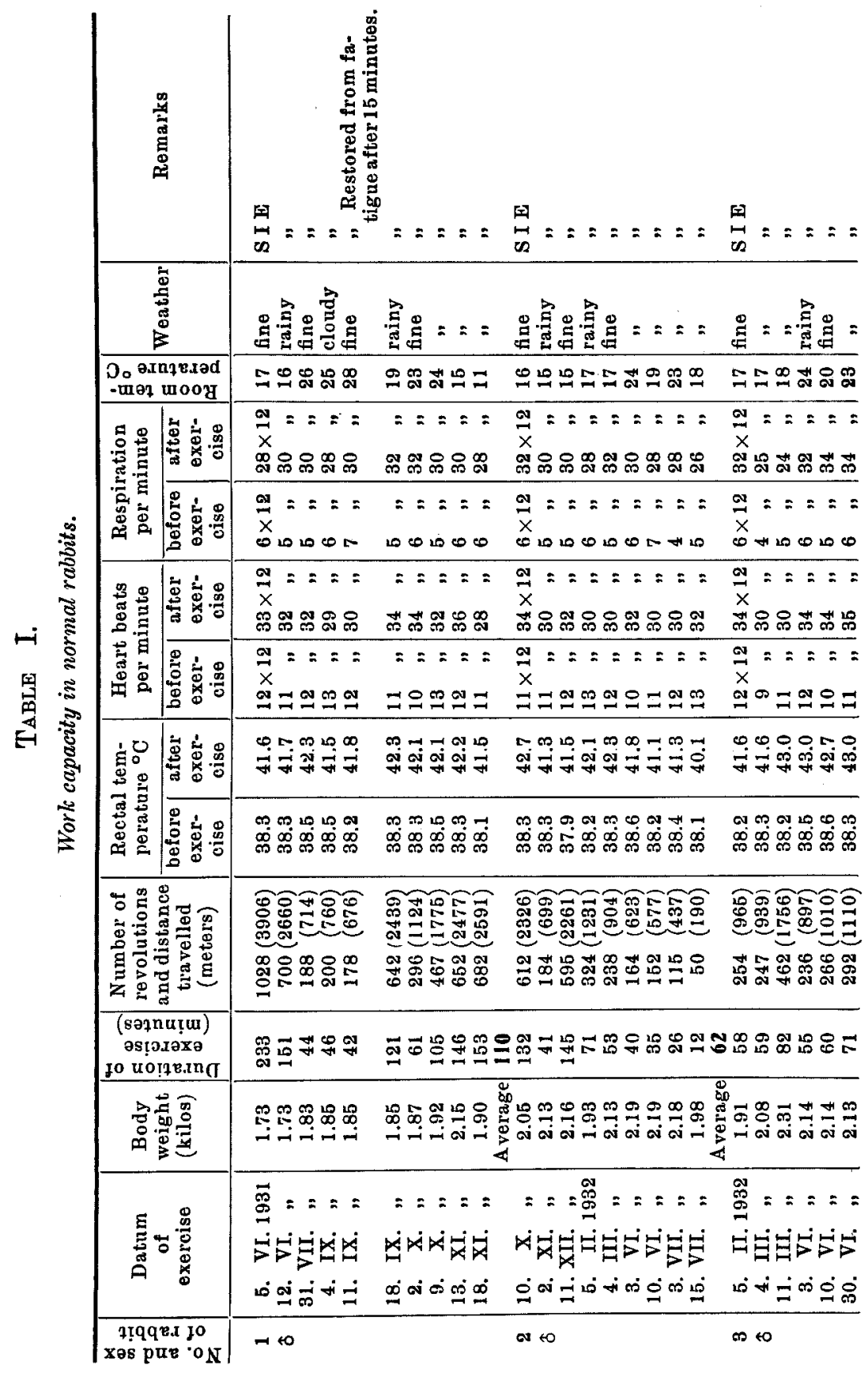




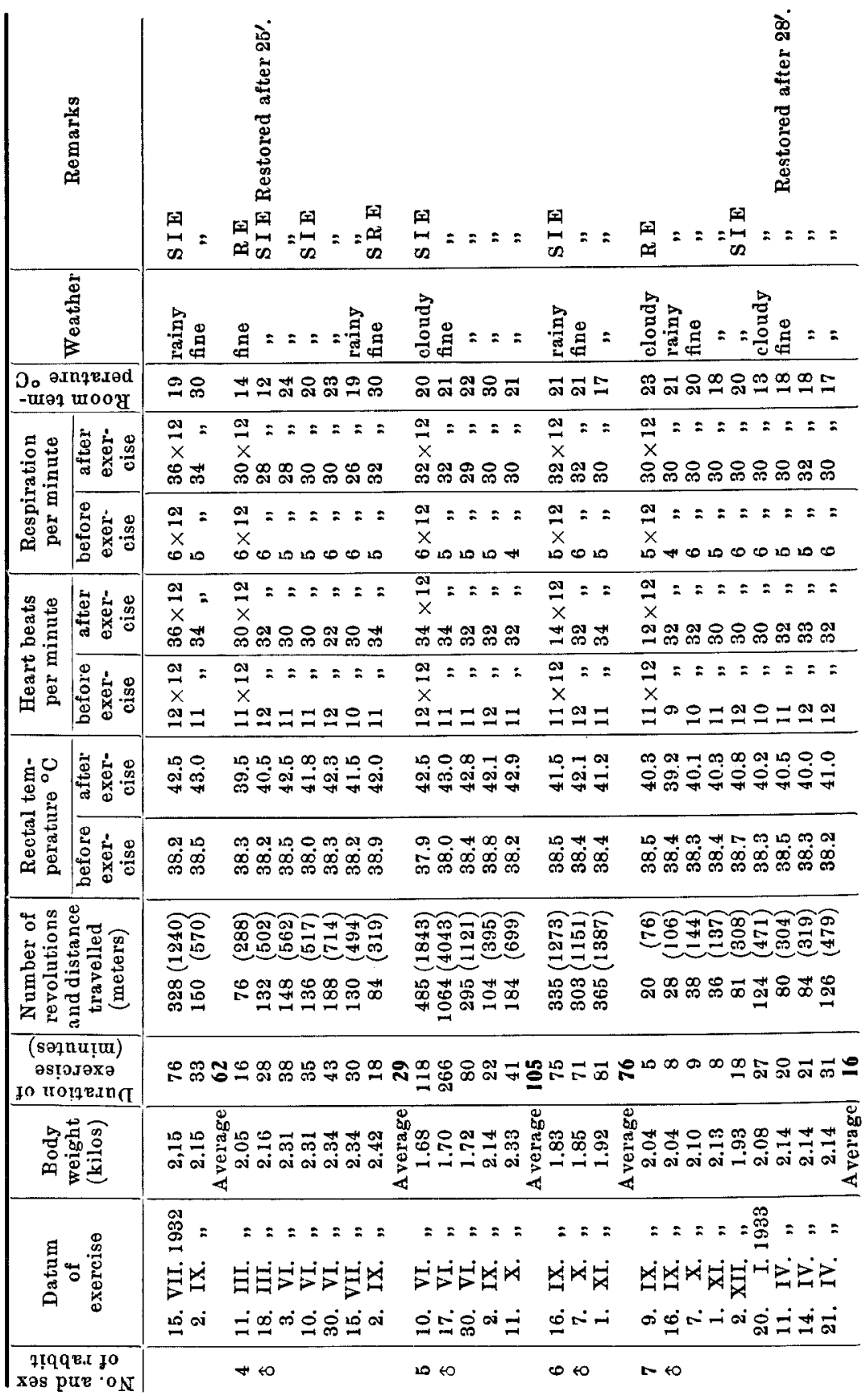




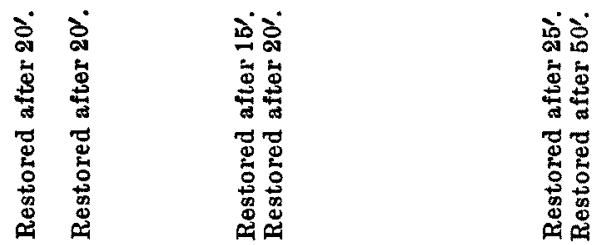

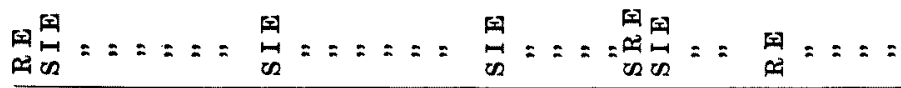

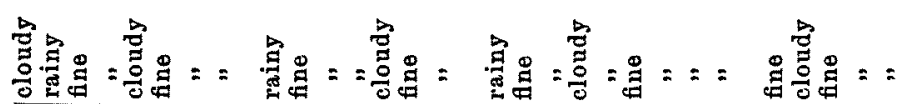

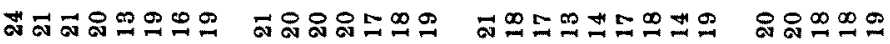

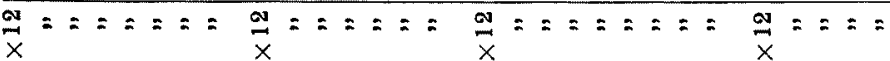

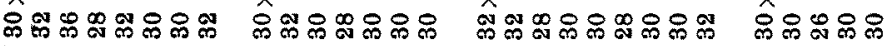

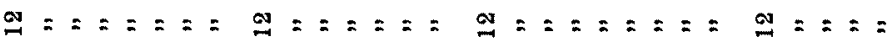

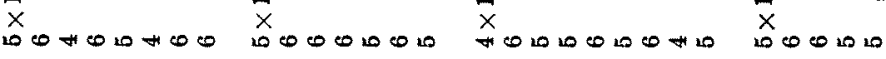

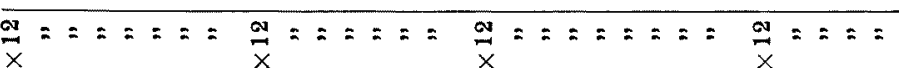

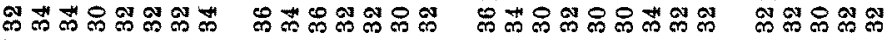

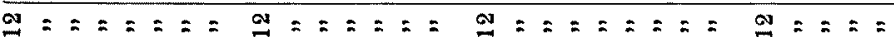

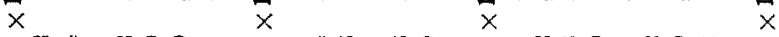

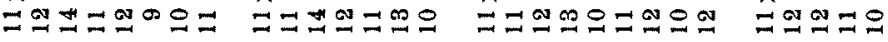

ח

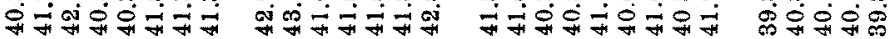

ט

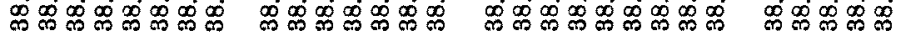

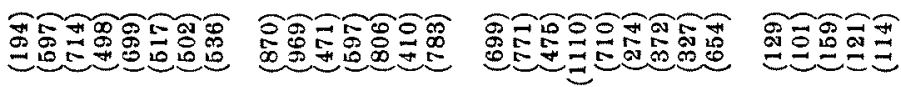

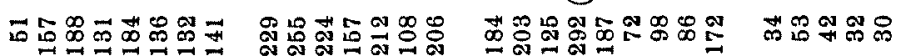

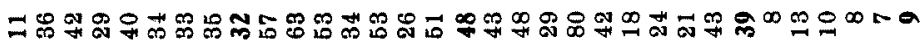

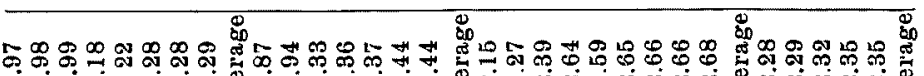

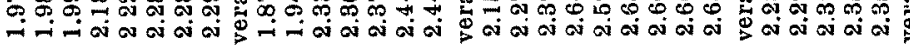
4 4 4

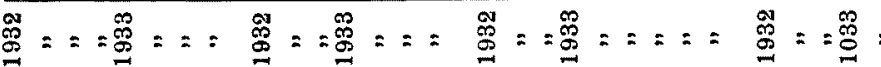

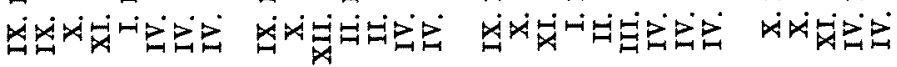

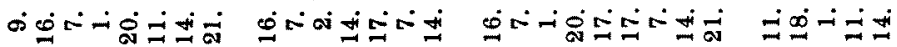

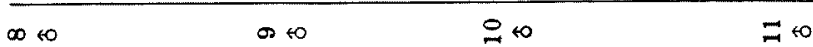




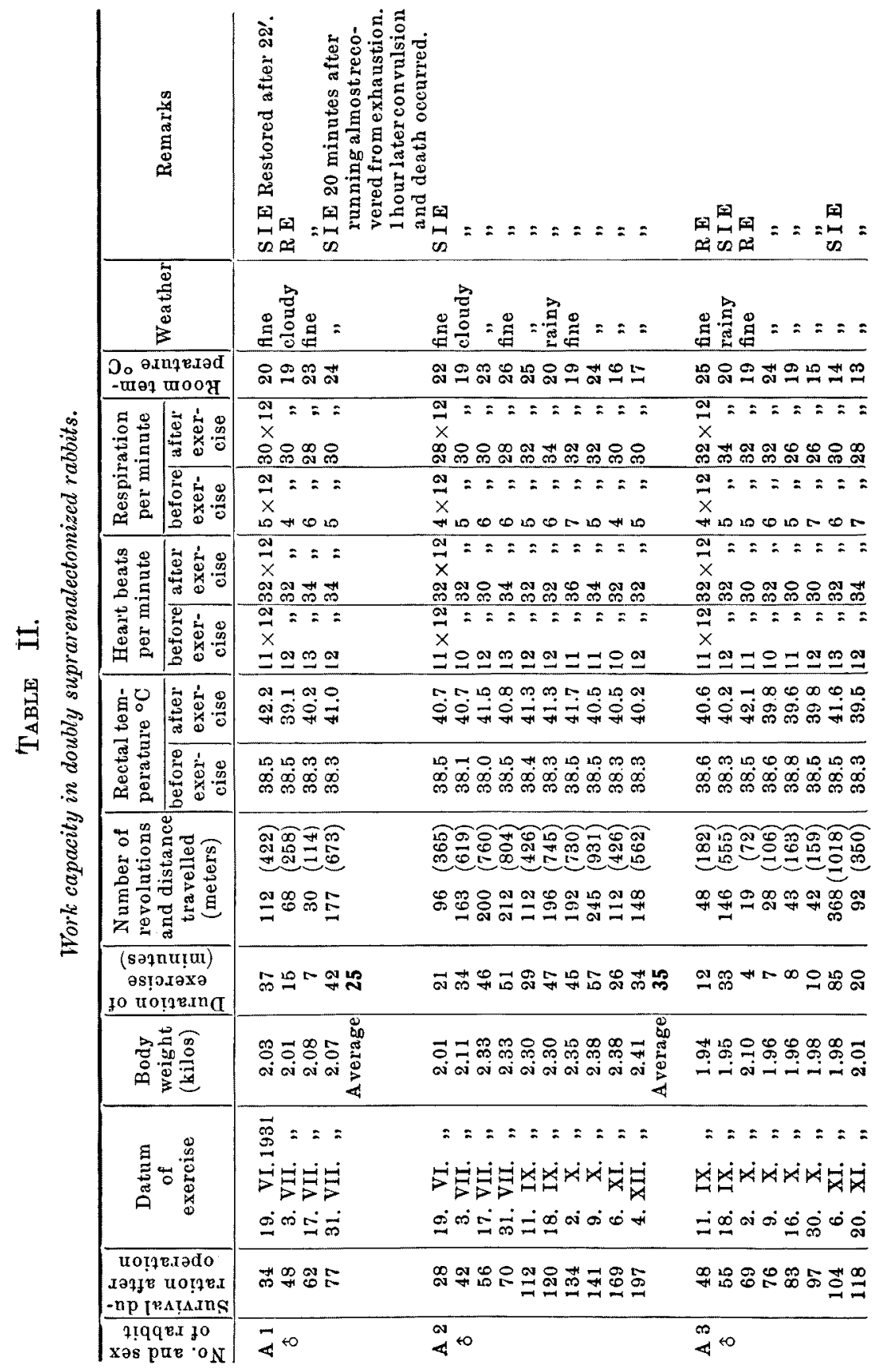




\begin{tabular}{|c|c|c|c|}
\hline 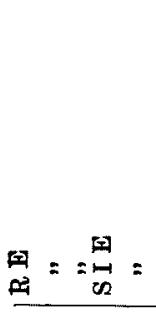 & 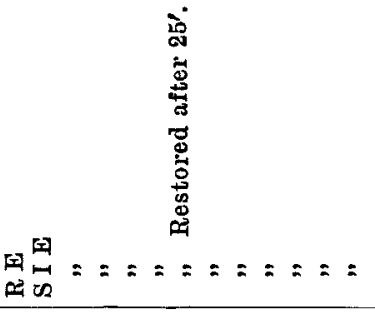 & 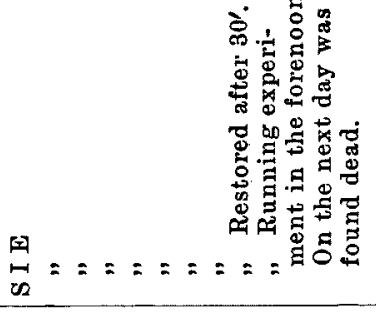 & $\frac{n}{n}===$ \\
\hline$=2=2=$ & 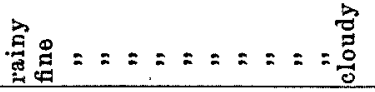 & 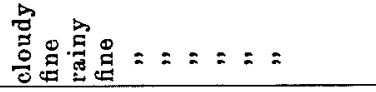 & $\stackrel{0}{\rightleftarrows}==2=$ \\
\hline 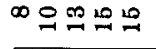 & 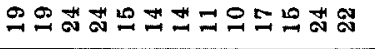 & 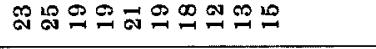 & 늡さ兄 \\
\hline 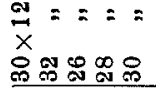 & 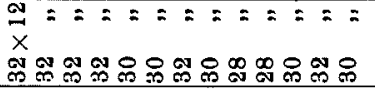 & 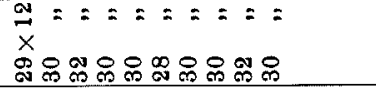 & 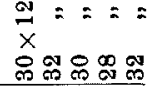 \\
\hline $\begin{array}{l}\frac{0}{2}=== \\
x=0100=\end{array}$ & 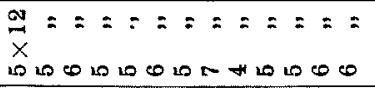 & 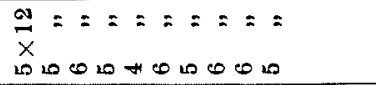 & $\begin{array}{l}\text { a }==:= \\
\vec{x}=0<-200 \\
000\end{array}$ \\
\hline 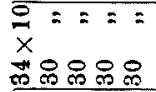 & 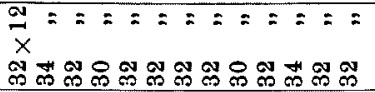 & 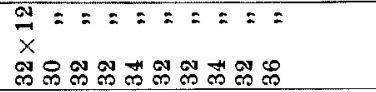 & 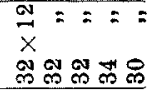 \\
\hline $\begin{array}{l}\underline{x}=:== \\
\underline{x}=\underline{\underline{N}}=\end{array}$ & 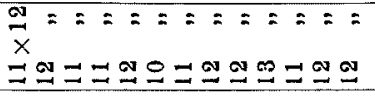 & 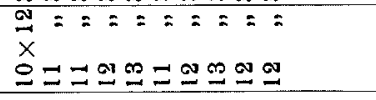 & 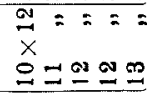 \\
\hline 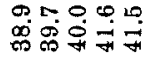 & 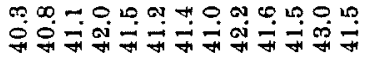 & 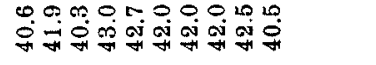 & 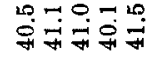 \\
\hline 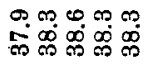 & 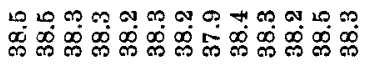 & 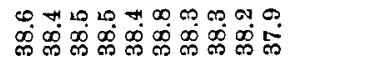 & 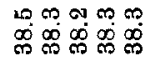 \\
\hline 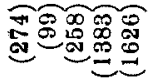 & 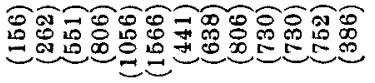 & 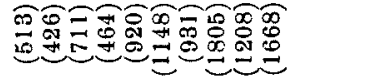 & $\begin{array}{l}\infty \\
0 \\
0 \\
0\end{array}$ \\
\hline 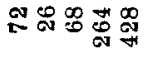 & 군 & 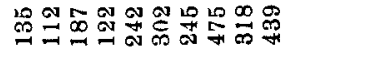 & 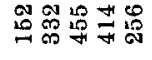 \\
\hline
\end{tabular}

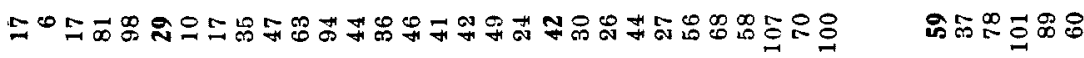

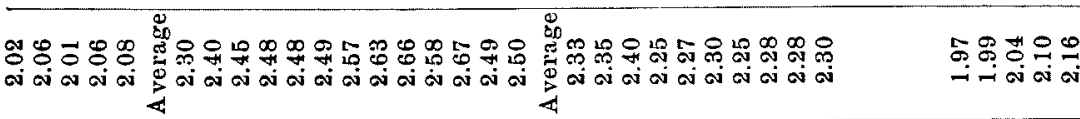

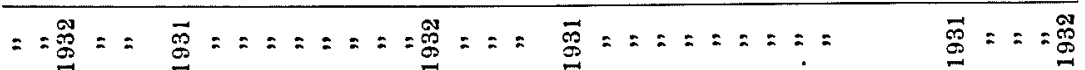

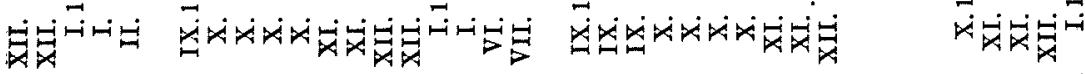

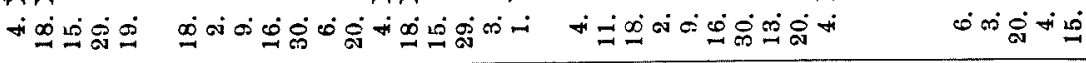

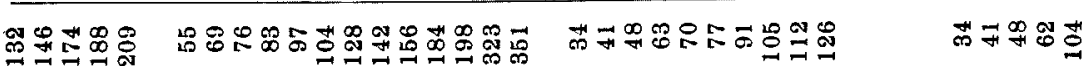

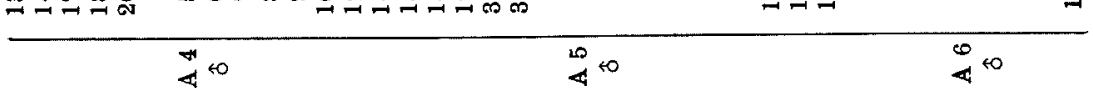




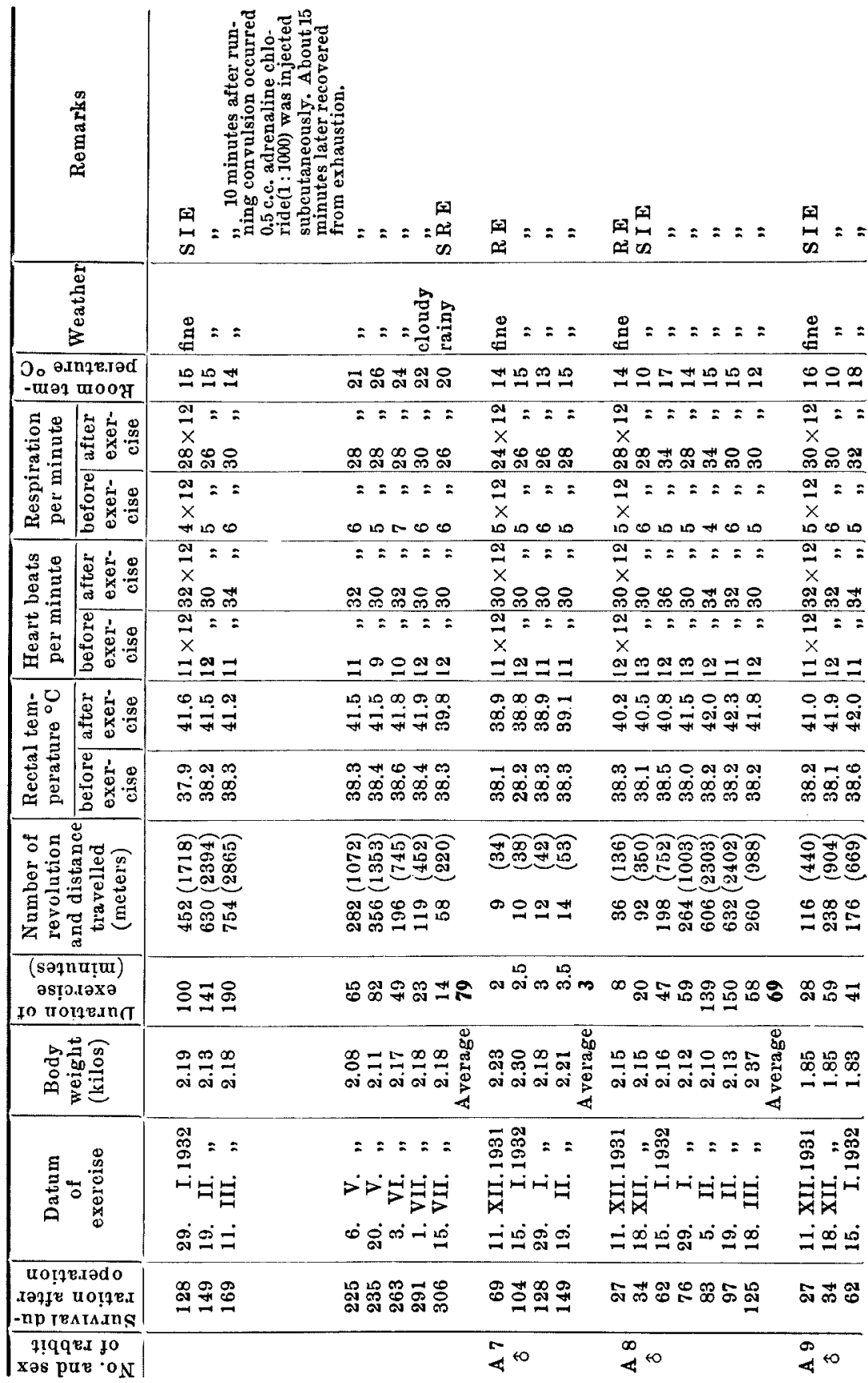




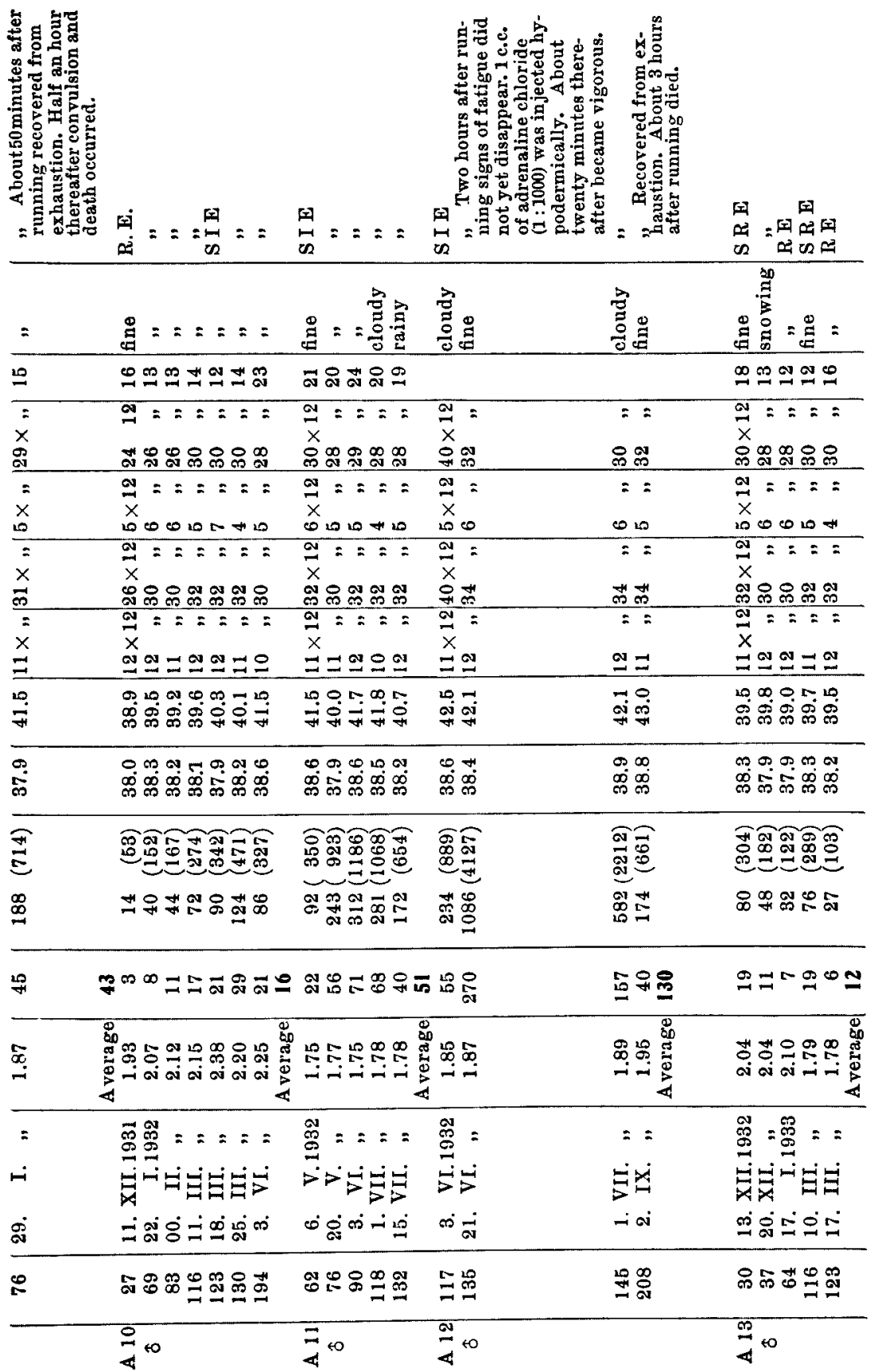




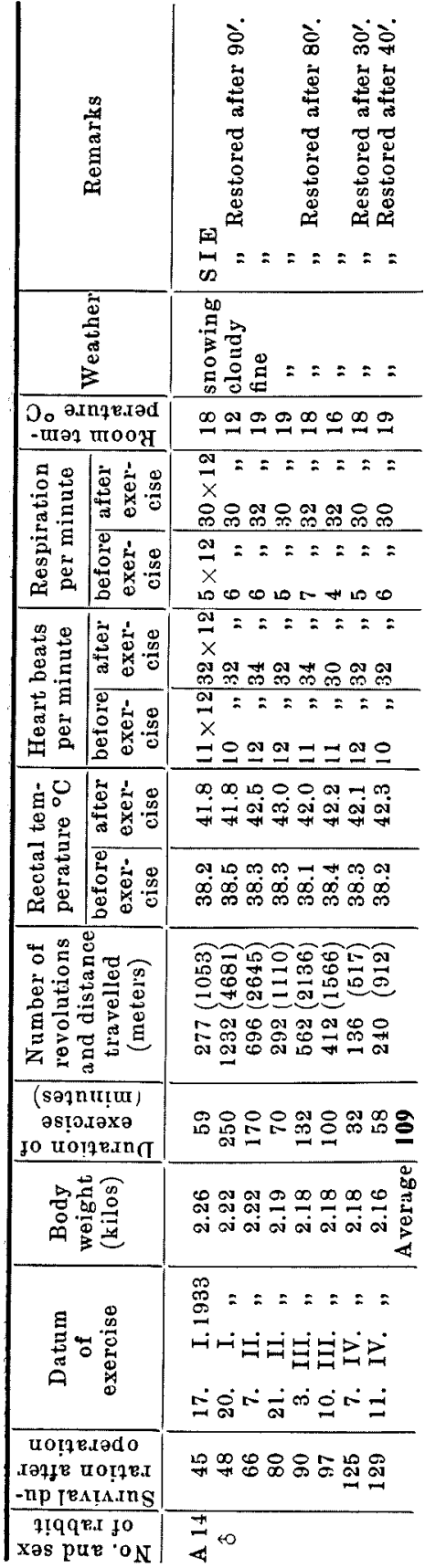

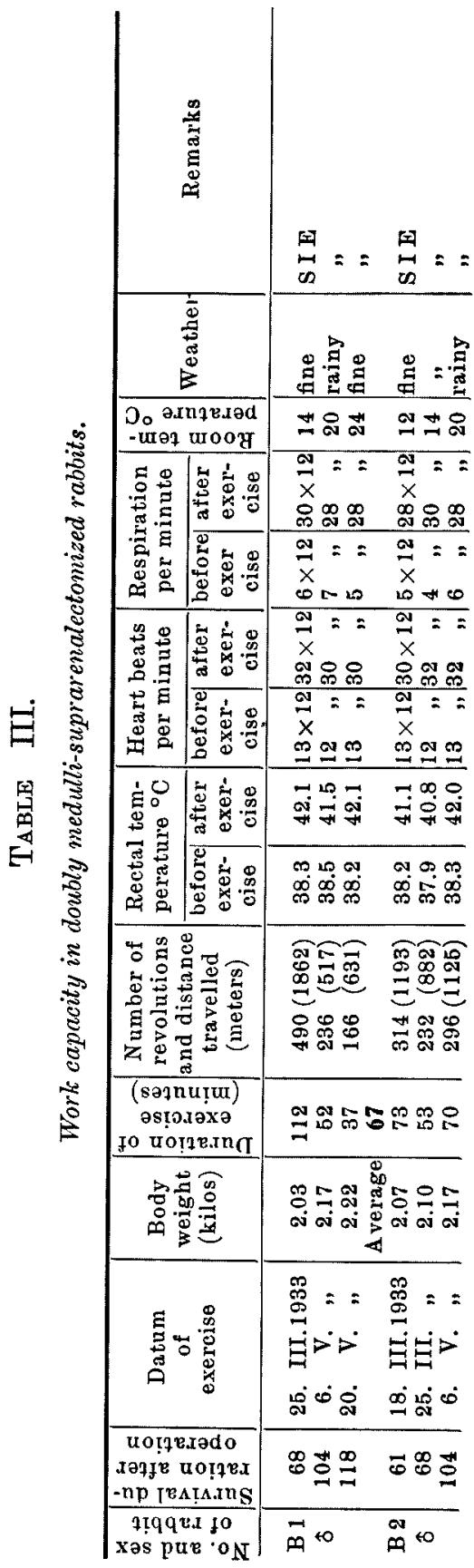




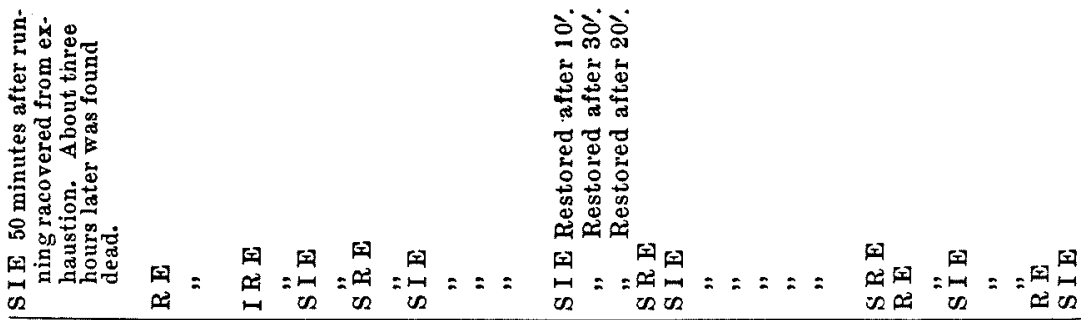

\begin{tabular}{|c|c|c|c|c|}
\hline$\stackrel{0}{:}$ & $\frac{D_{\overparen{E}}^{D}}{0}=$ & 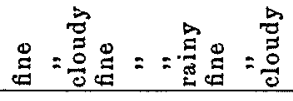 & 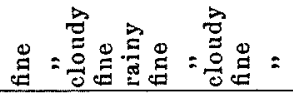 & 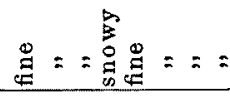 \\
\hline$\vec{N}$ & 워 & 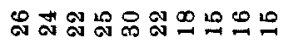 & 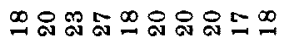 & 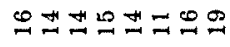 \\
\hline $\begin{array}{l}\bar{\alpha} \\
\dot{x} \\
\hat{m} \\
\underline{m}\end{array}$ & $\begin{array}{l}\infty \\
\stackrel{N}{X}= \\
\stackrel{\infty}{\infty}\end{array}$ & 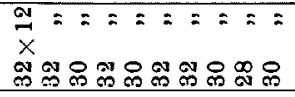 & 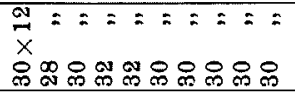 & 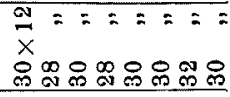 \\
\hline $\begin{array}{l}2 \\
x \\
\dot{0} \\
\end{array}$ & $\frac{0}{x}=$ & 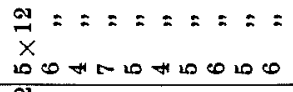 & 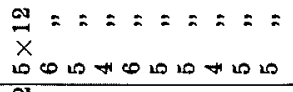 & $\begin{array}{l}\frac{a}{x}=2==2= \\
\frac{x}{100} 00+100000+1\end{array}$ \\
\hline $\begin{array}{l}\vdots \\
\dot{x} \\
d \\
d\end{array}$ & 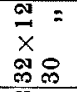 & 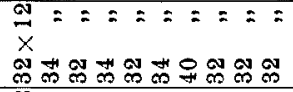 & 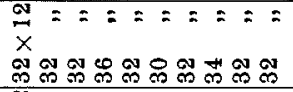 & 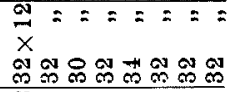 \\
\hline $\begin{array}{l}2 \\
x \\
\end{array}$ & $\begin{array}{l}a \\
\vec{x} \\
a \\
a\end{array}$ & 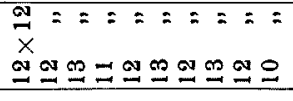 & 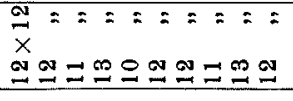 & 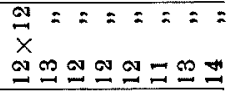 \\
\hline$\stackrel{\circ}{\dddot{m}}$ & 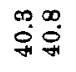 & 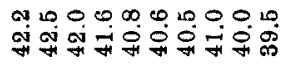 & 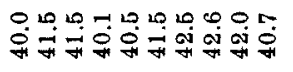 & 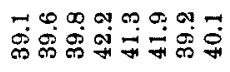 \\
\hline$\stackrel{10}{\infty}$ & $\infty_{\infty}^{\infty}$ & 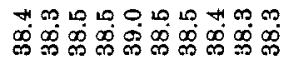 & 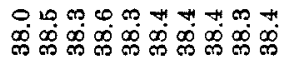 & 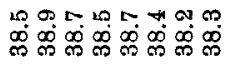 \\
\hline 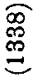 & $\stackrel{\infty}{\infty} 9$ & 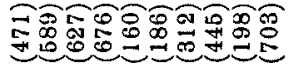 & 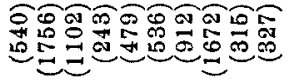 & 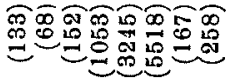 \\
\hline 点 & พิ & 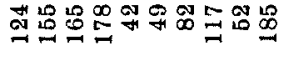 & 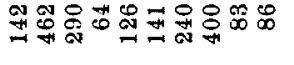 & 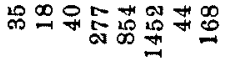 \\
\hline
\end{tabular}

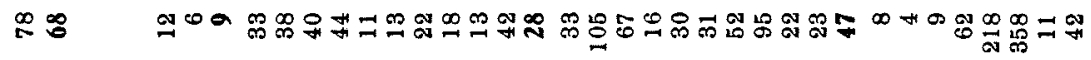

\begin{tabular}{|c|c|c|c|c|}
\hline 尊 & as & 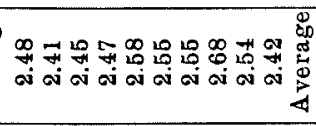 & 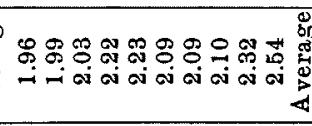 & 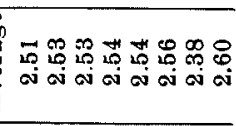 \\
\hline$=$ & $=:$ & 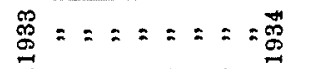 & $\underset{\mathscr{D}}{\mathscr{D}}===2===2 \underset{0}{\mathbb{D}}$ & 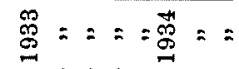 \\
\hline$>$ & 吕㟔 & 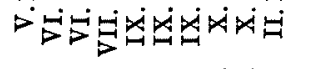 & 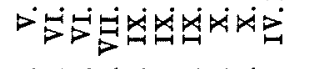 & 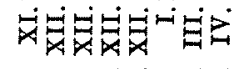 \\
\hline 今े & $m-i$ & 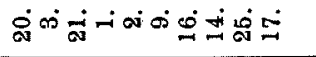 & 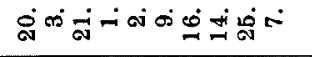 & $\doteq$ ब \\
\hline$\stackrel{\infty}{=}$ & 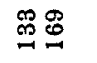 & 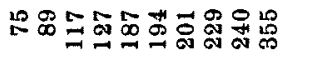 & 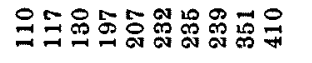 & 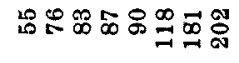 \\
\hline & $\mathbb{n}_{n}^{\infty}$ to & 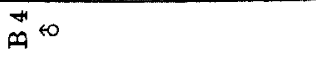 & $\infty_{\infty}^{\infty}$ to & $\stackrel{0}{m}+0$ \\
\hline
\end{tabular}




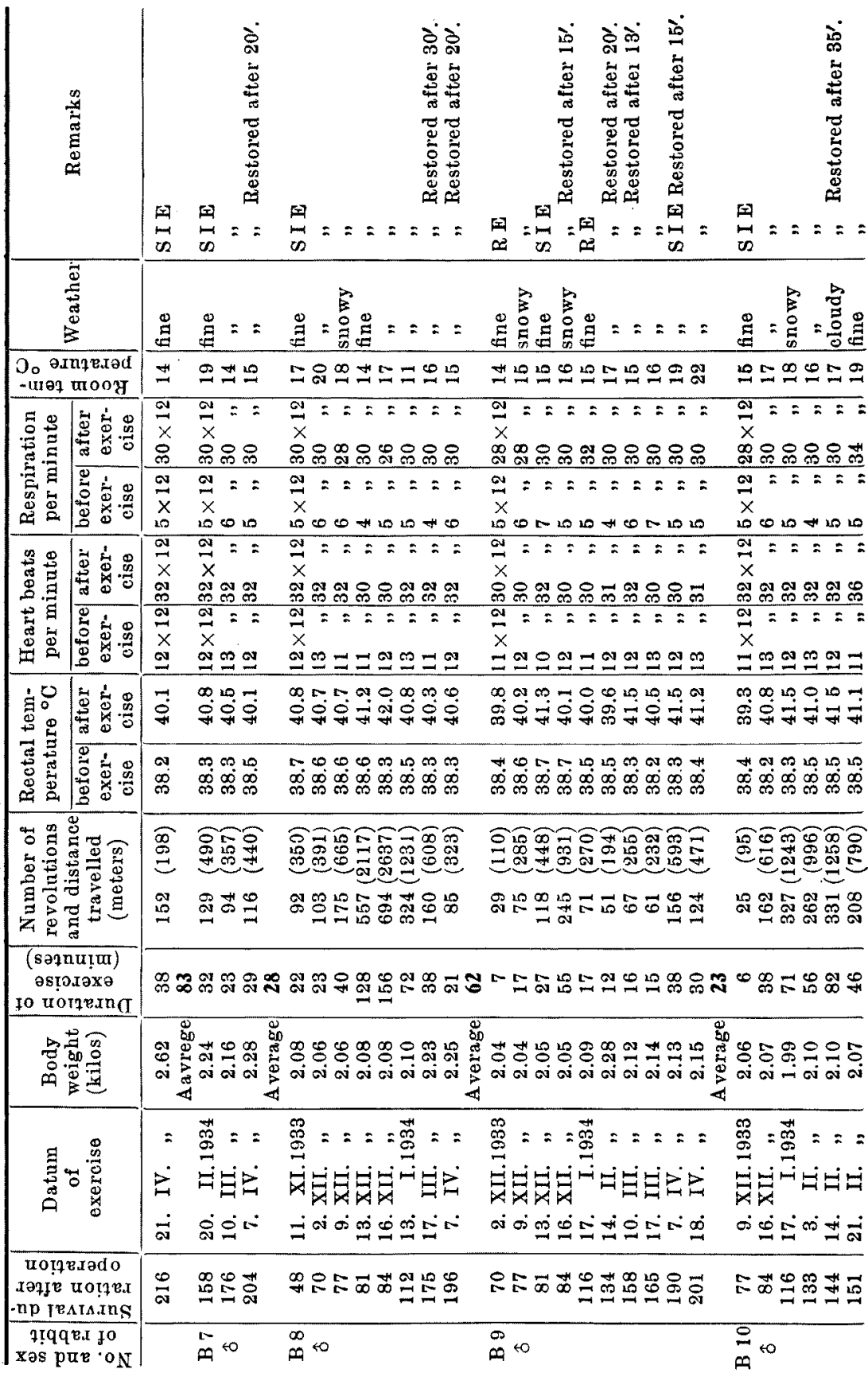




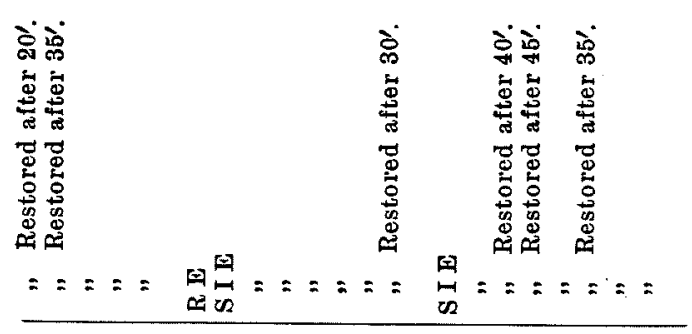

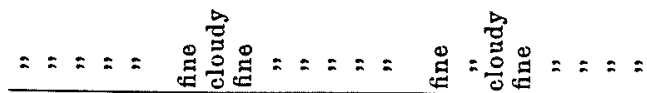

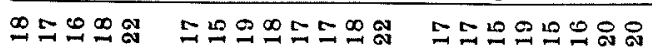

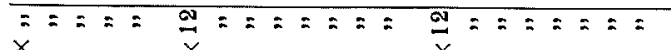

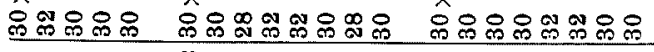

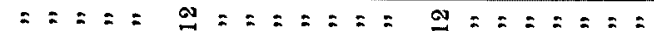
$x \quad x \quad a$

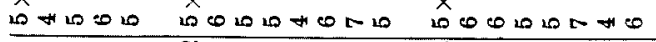

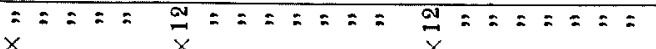

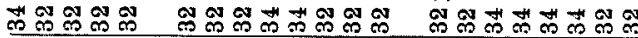

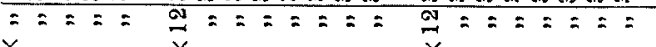
$x \quad x \quad=a=a=a x$

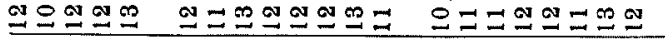

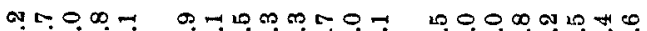

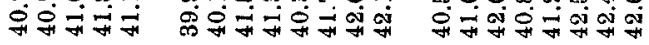

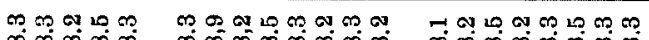

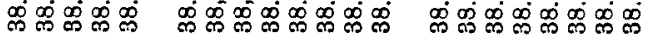

วิ응

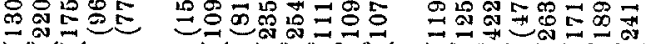

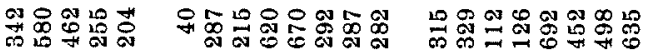

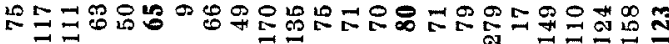

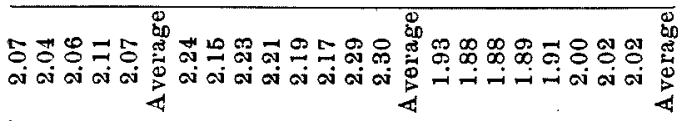

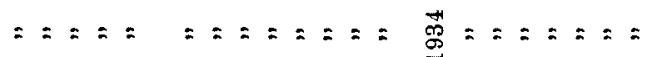

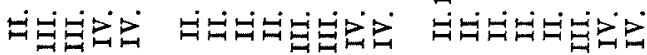

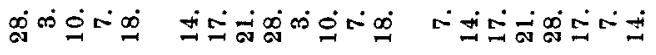

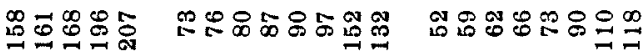

$\vec{m}$ 地 $\stackrel{\infty}{\infty}$ to

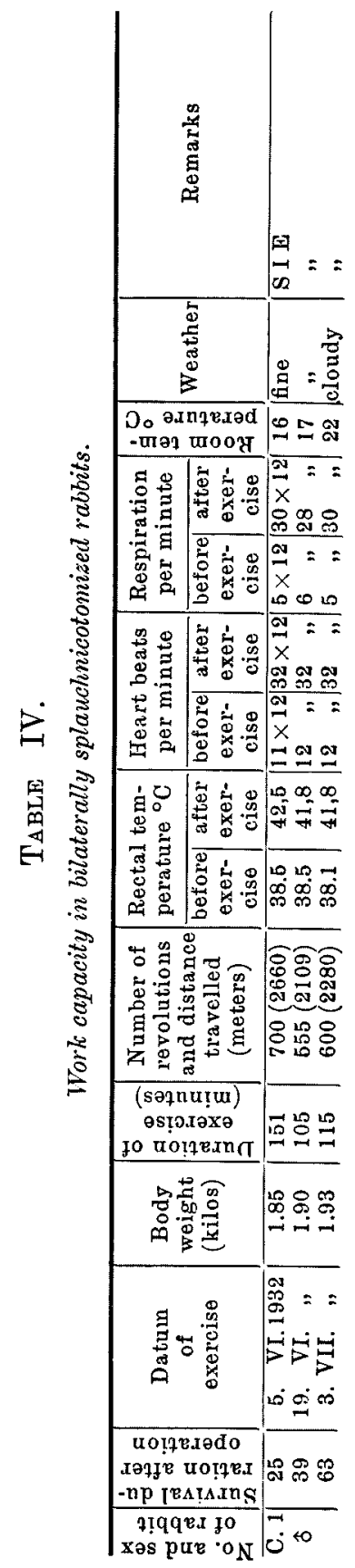




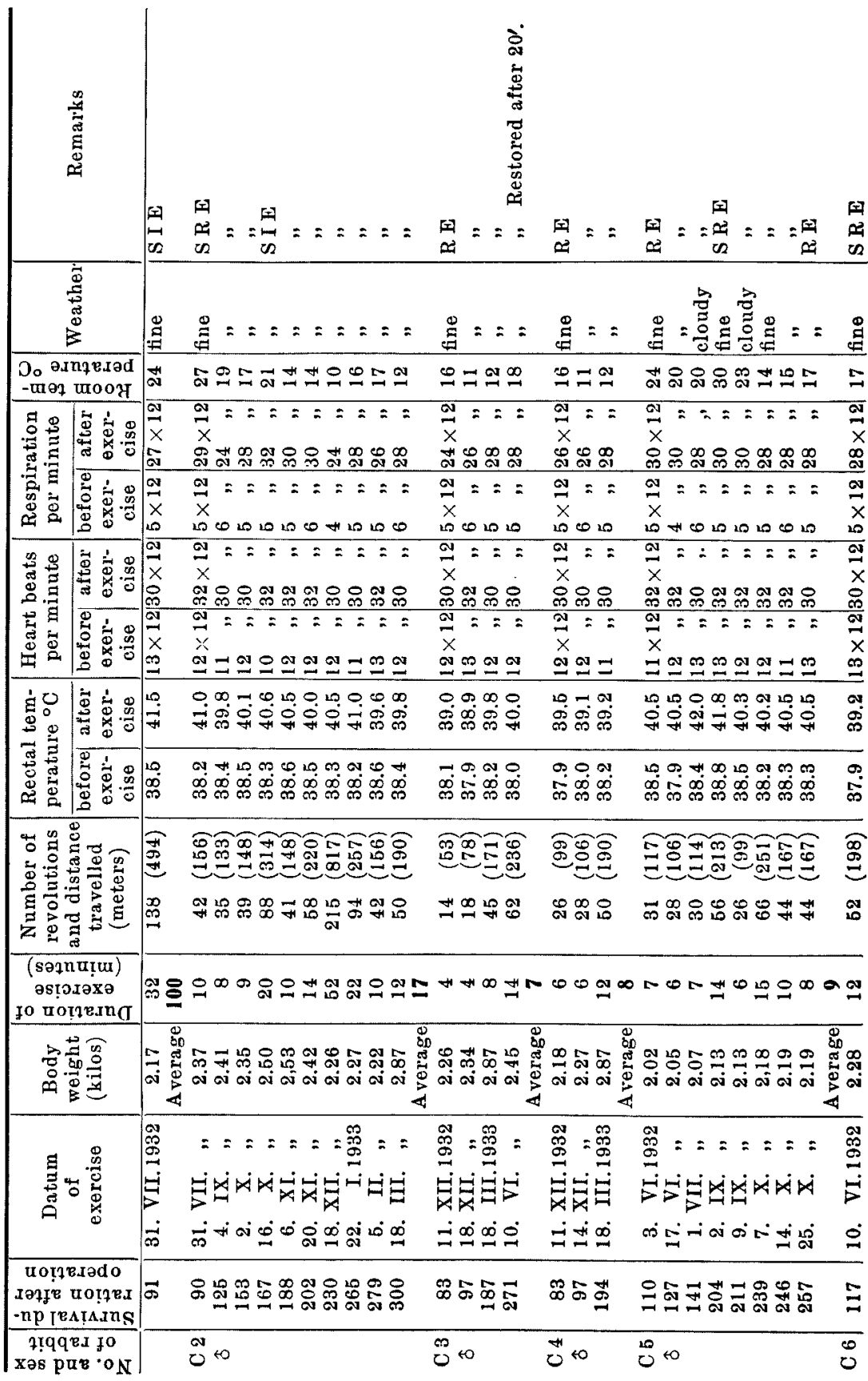




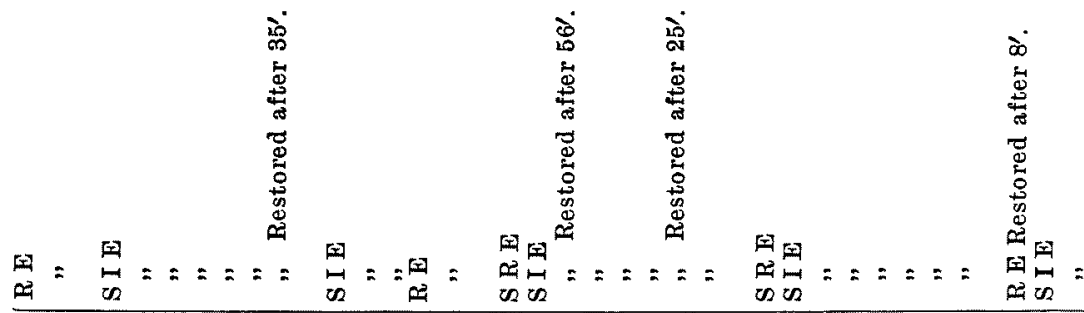

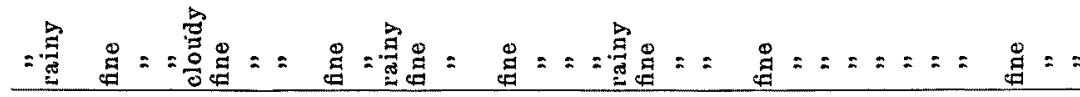

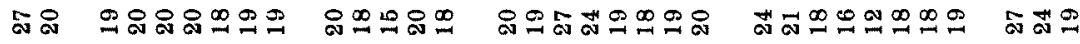

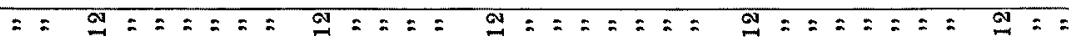

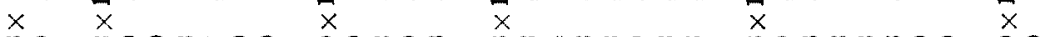

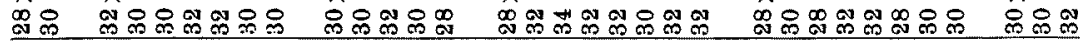

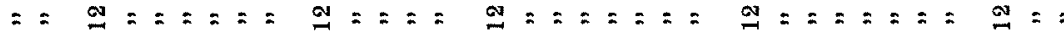
$x, x$

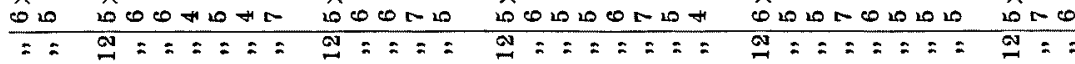
$x=\bar{x} \quad \bar{x} \quad \bar{x} \quad \bar{x}$

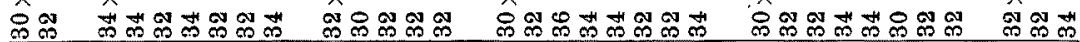

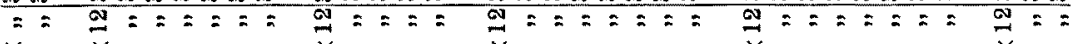
$x \quad x \quad x \quad x \quad x \quad x \quad x$

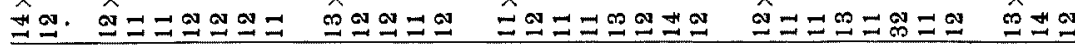

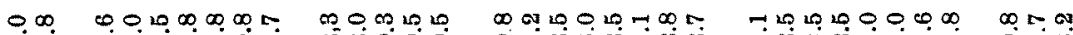

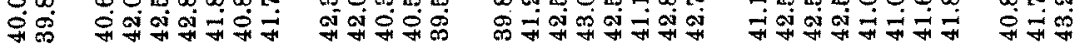

10 m क

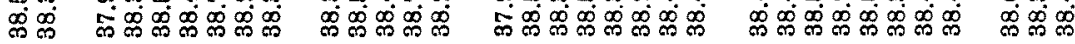

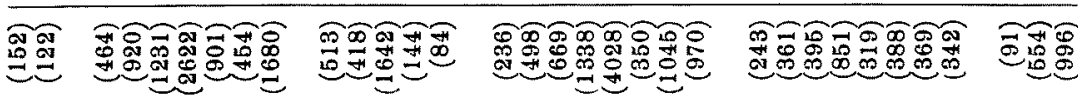

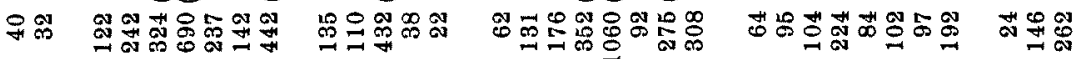

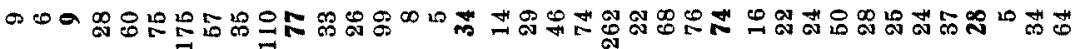

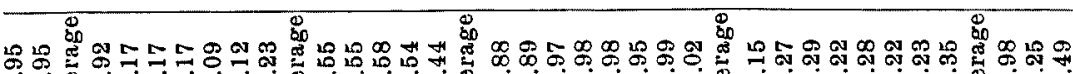

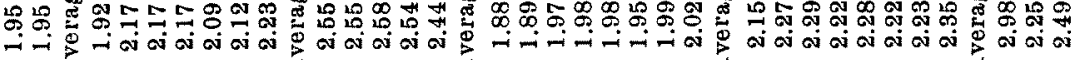

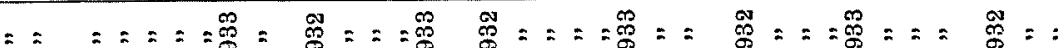

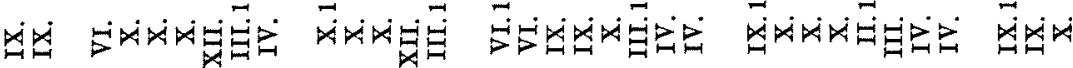
மீ

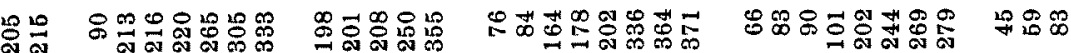

\begin{tabular}{lllll}
\hline 0 & 0 & $\infty$ & 0 & 0
\end{tabular}




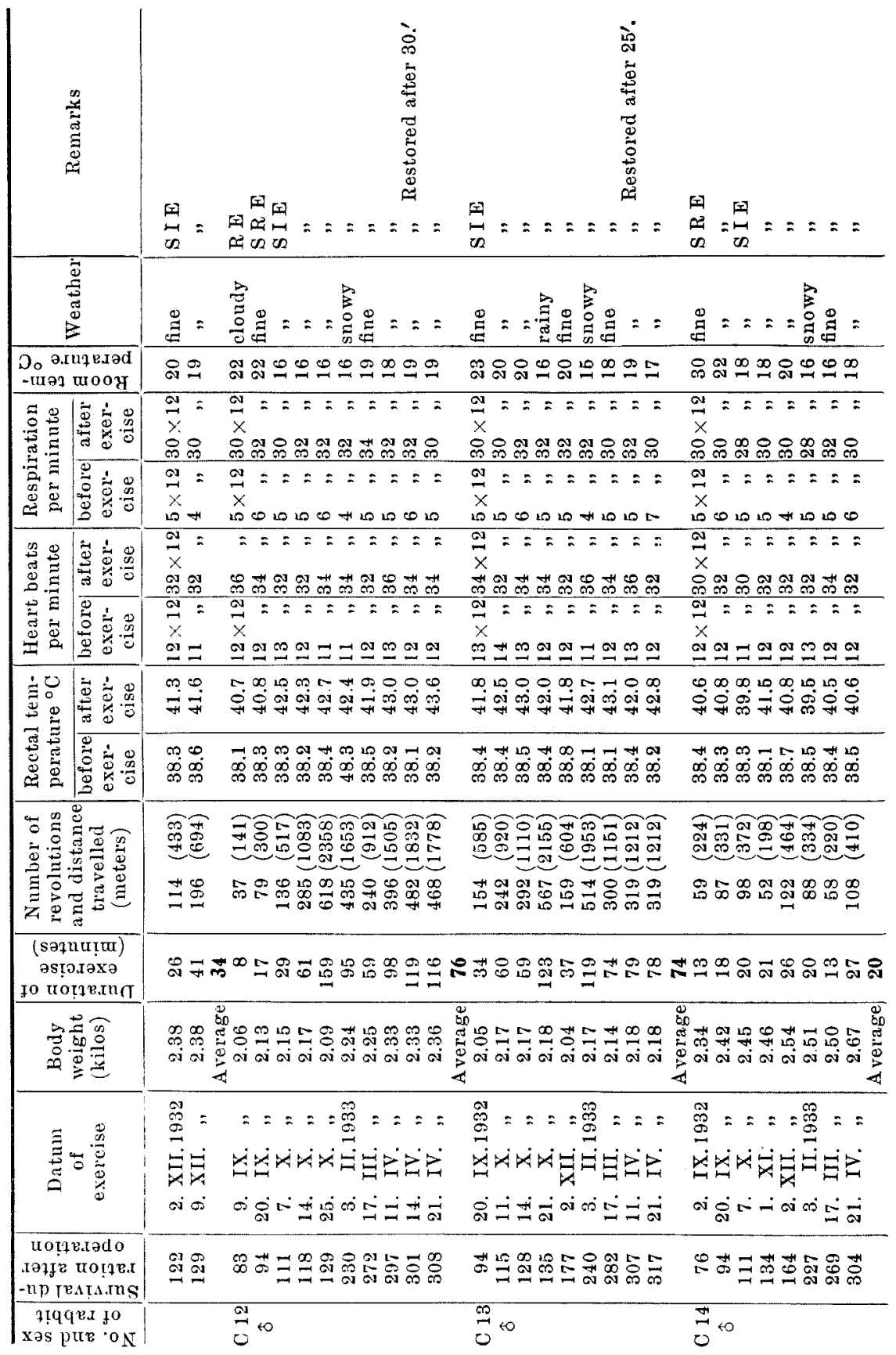

